\title{
Discrete Monetary Policy Changes and Changing Inflation Targets in Estimated Dynamic Stochastic General Equilibrium Models
}

\author{
Anatoliy Belaygorod and Michael J. Dueker
}

\begin{abstract}
Many estimated macroeconomic models assume interest rate smoothing in the monetary policy equation. In practice, monetary policymakers adjust a target level for the federal funds rate by discrete increments. One often-neglected consequence of using a quarterly average of the daily federal funds rate in empirical work is that any change in the target federal funds rate will affect the quarterly average in the current quarter and the subsequent quarter. Despite this clear source of predictable change in the quarterly average of the federal funds rate, the vast bulk of the literature that estimates policy rules ignores information concerning the timing and magnitude of discrete changes to the target federal funds rate. Consequently, policy equations that include interest rate smoothing inadvertently make the strong and unnecessary assumption that the starting point for interest rate smoothing is last quarter's average level of the federal funds rate. The authors consider, within an estimated general equilibrium model, whether policymakers put weight on the end-ofquarter target level of the federal funds rate when choosing a point at which to smooth the interest rate.
\end{abstract}

Federal Reserve Bank of St. Louis Review, November/December 2005, 87(6), pp. 719-33.

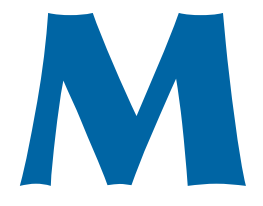

acroeconomic models that are linearized reduced forms of dynamic stochastic general equilibrium (DSGE) models with sticky prices are now widely considered to be ready for prime time-in the sense that they can confront the data, yield sensible parameter estimates, and provide useful policy analysis (Christiano, Eichenbaum, and Evans, 2005; Smets and Wouters, 2003 and 2005; McCallum and Nelson, 1999). With specific reference to monetary policy, DSGE models have begun to address two issues: whether policy rules are indeterminate and whether monetary policy rules include interest rate smoothing (Rotemberg and Woodford,
1999; Lubik and Schorfheide, 2004). The promise of estimated DSGE models is that one can take the parameter estimates, plug them into the underlying optimizing model, and perform welfare calculations. In this way, policymakers could get a handle on the welfare implications of key features of alternative monetary policy rules, such as the benefits of interest rate smoothing or the value of avoiding policy indeterminacy.

Prior to attempting such welfare calculations, however, it is worthwhile to refine the estimated monetary policy rule to reduce the scope of the mis-specification. In this article, we highlight ways to sharpen the specification of interest rate smoothing in DSGE models. In particular, we focus on a key issue that affects inferences regarding

Anatoliy Belaygorod is a Ph.D. candidate at the John M. Olin School of Business at Washington University. Michael J. Dueker is an economist and assistant vice president at the Federal Reserve Bank of St. Louis. The authors thank participants at the November 2004 Bundesbank DSGE conference, at which an earlier draft of this paper was presented, and the paper's discussant for his comments. They also thank Siddhartha Chib, James Bullard, Edward Nelson, and Michael Pakko for helpful discussions. Anatoliy Belaygorod was a visiting scholar at the St. Louis Federal Reserve Bank at the time this paper was written.

(C) 2005, The Federal Reserve Bank of St. Louis. Articles may be reprinted, reproduced, published, distributed, displayed, and transmitted in their entirety if copyright notice, author name(s), and full citation are included. Abstracts, synopses, and other derivative works may be made only with prior written permission of the Federal Reserve Bank of St. Louis. 
interest rate smoothing: the discreteness of monetary policy changes.

In practice, the Federal Open Market Committee adjusts a target level for the federal funds rate by discrete increments at their regularly scheduled meetings or in conference calls. One often-neglected consequence of using a quarterly average of the daily federal funds rate in empirical work is that any change in the target federal funds rate will affect the quarterly average in two different quarters. For example, if policymakers raise the target by 50 basis points precisely halfway through this quarter, then the current quarter's average will rise by 25 basis points relative to last quarter and next quarter's average will also exceed this quarter's average by 25 basis points, all else equal.

Despite this clear source of predictable change in the quarterly average of the federal funds rate, the vast bulk of the literature that estimates policy rules uses a monthly or quarterly average of the interest rate, yet ignores information concerning the timing and magnitude of discrete changes to the target federal funds rate. As a result, such empirical models end up trying to predict the effect on the quarterly average of known, past policy actions rather than including this piece of data in the forecast information set. Consequently, policy equations that include interest rate smoothing inadvertently make the strong and unnecessary assumption that the starting point for interest rate smoothing is last quarter's average level of the federal funds rate. It seems clear, however, that policymakers would put weight on the end-ofquarter target level of the federal funds when choosing a point at which to smooth the interest rate.

\section{INTEREST RATE SMOOTHING: AN UNSETTLED ISSUE}

One cart-versus-horse issue in empirical macroeconomics is whether monetary policymakers adjust the federal funds rate gradually in response to developments in the economy or, alternatively, whether developments in the economy emerge slowly enough to account for the slug- gish pace of observed changes in the interest rate. Sack (2000) and Clarida, Galí, and Gertler (2000) emphasize interest rate smoothing; Rudebusch (2002) believes that factors omitted from the empirical policy equation account for the apparent sluggishness of interest rate changes; English, Nelson, and Sack (2003) find evidence of both. The question is whether policymakers overtly decide to adjust the federal funds rate gradually. Three reasons have been put forth for rate smoothing and partial adjustment. First, policymakers are uncertain about the true structure of the economy; and this potential source of policy error leads them to act less forcefully than they otherwise would (Sack, 2000). Second, policymakers are similarly hesitant to act on initial data releases that are subject to subsequent revision (Orphanides, 2001).

Third, Woodford $(2003 a, b)$ suggests that monetary policymakers can influence market expectations if they show a willingness to implementeven through gradual actions-a large interest rate response if it proves necessary. For example, suppose that policymakers indicate that they are willing to raise the federal funds rate by an eventual amount of 120 basis points if a 40-basis-point increase in inflation persists. Policymakers demonstrate this willingness by embarking on a path of raising the interest rate gradually. If the public believes that this gradual path will be implemented for as long as necessary to reduce inflation, market expectations will adjust quickly, with the beneficial effect of reducing inflation without requiring much actual increase in the interest rate. Another way to state the Woodford scenario is to say that interest rate smoothing raises the unconditional variance of the interest rate relative to the variance of inflation, and the latter depends on the expectations of agents. Faced with this policy, the welfare-maximizing response of agents is to minimize the variance of inflation to reduce the realized fluctuations in the nominal and real interest rates.

\section{DISCRETE TARGET CHANGES AND INTEREST RATE SMOOTHING}

In the standard setup, interest rate smoothing takes the form 


\section{Figure 1}

\section{Discreteness Adjustment from Time $t-1$ and Change of Quarterly Average of Federal Funds Rate at Time $t$}



$$
R_{t}=\rho_{R} R_{t-1}+\left(1-\rho_{R}\right) \hat{R}_{t},
$$

where $R_{t}$ is the quarterly average of the federal funds rate and $\hat{R}$ is the desired rate based on current economic conditions, such as the Taylor rule-implied level. As discussed here previously, one shortcoming of equation (1) is that the most recent quarterly average, $R_{t}$, is assumed to be the reference point for interest rate smoothing, despite the fact that policymakers are apt to take into consideration the most recent target level of the federal funds rate, denoted $R_{t-1}^{T}$. Our empirical specification of an interest rate smoothing policy equation would be

$$
R_{t}=\rho_{R}\left[(1-\delta) R_{t-1}+\delta R_{t-1}^{T}\right]+\left(1-\rho_{R}\right) \hat{R}_{t},
$$

where $\delta$ indicates the weight given to $R_{t-1}$ versus $R_{t-1}^{T}$ in determining the starting point for interest rate smoothing. An equivalent way to write equation (2) is

(3) $R_{t}=\rho_{R} R_{t-1}+\left(1-\rho_{R}\right) \hat{R}_{t}+\left(\rho_{R}+D\right)\left(R_{t-1}^{T}-R_{t-1}\right)$, where $D=(\delta-1) \rho_{R}$. Viewed this way, $R_{t-1}^{T}-R_{t-1}$ is a discreteness-adjustment term appended to the basic interest rate smoothing equation. Dueker (2002) included such a discreteness-adjustment term in a vector autoregression, and Dueker and Rasche (2004) included it in an estimated Taylortype policy equation. Note that it is possible to find $D>0$, in which case $\delta>1$. The interpretation of this result would be that monetary policymakers do not use either $R_{t-1}$ or $R_{t-1}^{T}$ as the starting point for interest rate smoothing; instead, they use $R_{t-1}^{T}$ $+(\delta-1)\left(R_{t-1}^{T}-R_{t-1}\right)$,which implies that they impute some continuation of last period's target change(s) in the same direction into this quarter's baseline rate. That is, past target changes appear to imply some momentum for additional changes in the same direction. We might expect this type of momentum, given the way policymakers make relatively long series of target changes in the same direction. Figure 1 plots the changes in the quarterly average, $R_{t}-R_{t-1}$, with the discretenessadjustment term, $R_{t-1}^{T}-R_{t-1}$, for the federal funds rate. It is clear from the close correspondence that 
the discreteness-adjustment term is a predictor of changes in the quarterly average of the federal funds rate, based on target changes that took place in the previous quarter. Consequently, failure to include this term could affect estimated policy rules, especially with regard to interest rate smoothing. We turn next to the issue of policy indeterminacy.

\section{INDETERMINACY IN TAYLOR RULES}

A standard Taylor rule (Taylor, 1993) assumes that monetary policy operates through an interest rate rule that responds to expected inflation gaps and output gaps:

where $r^{*}$ is the steady-state real rate of interest, $\pi$ is inflation, $\pi^{*}$ is the long-run target rate of inflation, and $\widehat{G D P}$ is the gap between actual output and the level implied by the long-run balanced growth path. The policy rule in a standard DSGE model assumes a constant inflation target and subsumes $r^{*}$ and $\left(1-\psi_{1}\right) \pi^{*}$ together in the constant term:

$$
\hat{R}_{t}=\left[r^{*}+\left(1-\psi_{1}\right) \pi^{*}\right]+\psi_{1} \pi_{t}+\psi_{2} \widetilde{G D P}_{t}+\varepsilon_{R, t} .
$$

In a general equilibrium setting, a determinacy condition for monetary policy essentially states that the coefficient $\psi_{1}$ on inflation exceeds 1.0. Equation (5) suggests that indeterminacy results when policymakers are not responsive enough with their interest rate instrument to changes in inflation. Through the lens of equation (4), the determinacy condition requires that monetary policymakers make a positive interest rate response to an increase in the inflation gap. Not all increases in observed inflation would correspond one-to-one with an increase in the inflation gap if the target rate of inflation were not constant. To allow some sluggish interest rate adjustment to be the result of a changing inflation target and not the result of an indeterminate policy-similar to Smets and Wouters (2003), Gavin, Kydland, and Pakko (2005), Gavin,
Keen, and Pakko (2005), and Ireland (2005)—we allow the target rate of inflation, $\pi^{T}$, to vary across time as an autoregressive process with unconditional mean $\pi^{*}$ :

$$
\begin{aligned}
& \hat{R}_{t}=r^{*}+\pi_{t}+\left(\psi_{1}-1\right)\left(\pi_{t}-\pi_{t}^{T}\right)+\psi_{2} \widetilde{G D P}_{t}+\varepsilon_{R, t} \\
& \pi_{t}^{T}=\pi^{*}+\rho_{\pi}\left(\pi_{t-1}^{T}-\pi^{*}\right)+\varepsilon_{\pi, t},
\end{aligned}
$$

which is equivalent to

$$
\hat{R}_{t}=r^{*}+\pi_{t}^{T}+\psi_{1}\left(\pi_{t}-\pi_{t}^{T}\right)+\psi_{2} \widetilde{G D P}_{t}+\varepsilon_{R, t} .
$$

With a stationary autoregressive target rate of inflation, nominal variables have well-defined steady-state levels. Yet, there is an additional reason why the interest rate might be relatively unresponsive in the face of an increase in inflation: The inflation might be due to a temporary but persistent increase in the target level of inflation. With this additional fundamental shock, $\varepsilon_{\pi, t}$, it is possible that the parameter estimates differ enough from those in the restricted model to increase the posterior odds of determinacy. In other words, we might not need policy indeterminacy to help explain the complex interplay between the interest rate and inflation if the target rate of inflation is not assumed to be constant.

\section{THE DSGE MODEL}

We log-linearize the New Keynesian monetary DSGE model from Woodford (2003a,b) and express variables as deviations from the steady-state levels:

(8)

$$
\begin{aligned}
& \widetilde{G D P}_{t}=E_{t} \widetilde{G D P}_{t+1}-\tau\left(\tilde{R}_{t}-E_{t} \tilde{\pi}_{t+1}\right)+g_{t} \\
& \tilde{\pi}_{t}=\beta E_{t} \tilde{\pi}_{t+1}+\kappa\left(\widetilde{G D P}_{t}-z_{t}\right) \\
& \tilde{R}_{t}=\rho_{R} \tilde{R}_{t-1}+\left(\rho_{R}+D\right)\left(R_{t-1}^{T}-R_{t-1}\right) \\
& +\left(1-\rho_{R}\right)\left[\tilde{\pi}_{t}^{T}+\psi_{1}\left(\tilde{\pi}_{t}-\tilde{\pi}_{t}^{T}\right)+\psi_{2}\left(\widetilde{G D P}_{t}-z_{t}\right)\right]+\varepsilon_{R, t} \\
& \tilde{\pi}_{t}^{T}=\rho_{\pi} \tilde{\pi}_{t-1}^{T}+\varepsilon_{\pi, t},
\end{aligned}
$$

where $z$ is a technology shock, $g$ is a demand shock, $\pi_{t}^{T}$ is the target rate of inflation, $\varepsilon_{\pi}$ is the innovation to the target rate of inflation, and $\varepsilon_{R}$ is a monetary policy shock. The formal condition for determinacy in this model is that 


$$
\psi_{1}>1-\frac{\beta \psi_{2}}{\kappa}\left(\frac{1}{\beta}-1\right),
$$

which essentially means $\psi_{1}>1$, given that $\beta$, the time discount factor, is so close to 1 in these models.

In this paper, we estimate a model enriched with discreteness correction, $D \neq-\rho_{R}$, and a time-varying inflation target, $\varepsilon_{\pi} \neq 0$, assuming that during the sample period between 1984 and 2004 U.S. monetary policy was determinate-an assumption supported by a number of empirical studies, such as Lubik and Schorfheide (2004).

The discreteness-adjustment term, $R_{t-1}^{T}-R_{t-1}$, which is the gap between the end-of-quarter target level and the quarterly average of the federal funds rate, is largely a function of the timing of monetary policy meetings within a quarter. Other things equal, the later the meeting at which the target is changed, the larger will be the gap between the quarterly average and the end-of-quarter target. Because the calendar of monetary policy meetings, while important for forecasting the quarterly average of the federal funds rate, is not something we want to determine within the general equilibrium model, we treat the discreteness adjustment as a predetermined variable. In the appendix, we describe how to handle such a predetermined variable in the solution and estimation of the general equilibrium model. Lubik and Schorfheide (2004) derive a condition with which they express forecast errors strictly as a function of structural shocks in a determinate model. We want the predetermined variable, which is dated $t-1$, to affect only expected values at time $t$, not forecast errors, because rational expectations forecast errors are orthogonal to everything in the current information set. The mechanics of imposing this condition are spelled out in the appendix. In fact, these methods for dealing with predetermined variables are used in DSGE models of small open economies (Kollmann, 2001 and 2002), where rest-of-world variables are decomposed into expected and unexpected components. However, the DSGE solution methodology implemented in this literature is based on the older approach attributed to Blanchard and Kahn (1980). In this paper we are using a more recent and superior approach for solving DSGE models attributed to Sims (2002). It is important to make the following distinction here: While one of the main improvements of Sims (2002) over Blanchard and Kahn (1980) is the handling of the endogenous predetermined variables (which are elements of the state vector), our generalization of Sims (2002) comes from adding exogenous predetermined regressors. Obviously, by definition of being exogenous, such regressors cannot be elements of the state vector because the dynamics of their evolution are determined exogenously (outside this model's specification).

The quarterly data are gross domestic product (expressed in logs as the Hodrick-Prescott-filtered deviation from trend), inflation (measured as the percentage change in the personal consumption expenditures chain-weighted deflator), the quarterly average of the federal funds rate, and the predetermined discreteness-correction scalar, $\Delta_{t-1}=R_{t-1}^{T}-R_{t-1}$, where $t=1984: \mathrm{Q} 2, \ldots, 2004: \mathrm{Q} 2$. In the appendix, we describe how the DSGE solution procedure of Sims (2002) can be extended to handle predetermined variables, such as the discreteness adjustment, $\Delta_{t-1}$. We chose post-1984 data because we wanted a time period when U.S. monetary policy was unambiguously determinate. Data on a target federal funds rate are available for earlier time periods, although the exact dates and magnitudes of target changes are open to debate.

We use Kalman filter recursions to evaluate the likelihood function of the data. We apply Bayesian and maximum-likelihood estimation to this model. Our objective is not only to find the point estimates of the parameters, but also to plot the entire marginal posterior distribution for parameters of interest. This objective could be accomplished only in a Bayesian framework. Whether the Bayesian Markov chain Monte Carlo (MCMC) posterior densities look like the asymptotic normal distributions implied by maximumlikelihood estimation is an empirical question. Although Bayesian MCMC methods converge faster if supplied with the true maximumlikelihood parameter estimates and a smooth function surface, it is not a matter of necessity for the MCMC methods to work. To the extent that our proposal density is off the mark, our MCMC 


\section{Table 1}

\section{Parameter Estimates}

\begin{tabular}{lcc} 
Parameter & $\begin{array}{c}\text { Tailored } \\
\text { Metropolis-Hastings }(\mathrm{M}-\mathrm{H}) \\
\text { mean }\end{array}$ & $\begin{array}{c}\text { Standard } \\
\text { deviation }\end{array}$ \\
\hline$\tau$ & 0.31156 & 0.09457 \\
$\beta$ & 0.98946 & 0.00461 \\
$\kappa$ & 0.40955 & 0.10878 \\
$\psi_{1}$ & 2.22968 & 0.28474 \\
$\psi_{2}$ & 0.28733 & 0.09322 \\
$\rho_{\pi}$ & 0.77564 & 0.06405 \\
$\rho_{R}$ & 0.88040 & 0.02368 \\
$\rho_{g}$ & 0.86345 & 0.02954 \\
$\rho_{z}$ & 0.71307 & 0.04449 \\
$D$ & 0.19775 & 0.15038 \\
$\pi^{*}$ & 2.56057 & 0.30705 \\
$r^{*}$ & 1.71577 & 0.41087 \\
$\sigma_{R}$ & 0.08642 & 0.01096 \\
$\sigma_{z}$ & 0.70809 & 0.08030 \\
$\sigma_{g}$ & 0.11248 & 0.01739 \\
$\sigma_{\pi}$ & 0.22998 & 0.06885 \\
$\rho_{g z}$ & 0.80050 & 0.06404 \\
& &
\end{tabular}

NOTE: $10,000 \mathrm{M}-\mathrm{H}$ iterations including 10 percent burn-in. $\mathrm{M}-\mathrm{H}$ algorithm elapsed time was 55 seconds.

sampler will be less efficient and will require more draws, but the results will still be valid.

\section{ESTIMATION RESULTS}

For this sample period, we restrict the parameter space to the determinacy region. This restriction should not contradict the true distribution of the parameters in the post-1984 sample period. Table 1 presents the Bayesian MCMC parameter estimates for the full model estimated using a tailored Metropolis-Hastings (M-H) algorithm (Chib and Greenberg, 1994). ${ }^{1}$ For brevity, we do not report standard errors for the maximumlikelihood estimates because, for all four model specifications reported in Table 2, standard devi-

1 See Chib (1995, 1996, and 2001) for detailed discussion of the M-H theory and implementation. ations are very close to the corresponding values in Table 1. A key result is that, while both additions to the basic model-the discreteness adjustment and the time-varying inflation target-affect the parameter estimates relative to the basic model, especially in terms of reducing $\sigma_{R}$, the constant inflation target specification essentially does not change any other parameter within the full model. Thus, if one had to choose between dropping either the discreteness adjustment or the time-varying inflation target, the discreteness adjustment would be the one to keep. At the same time, both the discreteness adjustment and the time-varying inflation target yield lower estimates of the interest-sensitivity of output (lower $\tau$ ) and a steeper Phillips curve (lower $\kappa$ ), relative to the basic model. The discreteness adjustment reduces the estimates of these two parameters below that which the time-varying inflation target would imply alone.

The remainder of our discussion of the parameter estimates focuses on Bayesian MCMC estimates of the full model, for which we report standard deviations in Table 1. We also include plots of the smoothed normalized marginal posteriors (superimposed with the corresponding priors $^{2}$ ) for key parameters because such output is much more informative than point estimates and asymptotic standard errors. In addition, when forecasting, or drawing inferences about the latent variables, such as the target rate of inflation, we are not limited to point estimates of the parameters; instead, we can study the entire distribution of parameters and latent variables. We used this approach to estimate the dynamics of the latent inflation expectations and inflation target (see Figure 2).

The posterior means from the MCMC algorithm are close to the maximum-likelihood estimates. The very tight distribution for $\sigma_{R}$ shows that the basic model unambiguously forecasts the quarterly average of the federal funds rate worse than the enhanced model does. Thus, it clearly behooves models to take into account the effects of recent target changes when forecasting the

\footnotetext{
2 We used exactly the same priors as Lubik and Schorfheide (2004) for all common parameters.
} 


\section{Table 2}

Maximum Likelihood Parameter Estimates for the Full Model and for Three Reduced Models

\begin{tabular}{|c|c|c|c|c|}
\hline Parameters & Full model & $\begin{array}{c}\text { No discreteness } \\
\text { adjustment }\end{array}$ & $\begin{array}{c}\text { Constant } \\
\text { inflation target }\end{array}$ & $\begin{array}{c}\text { No discreteness } \\
\text { adjustment and } \\
\text { constant inflation target }\end{array}$ \\
\hline$\tau$ & 0.25649 & 0.33904 & 0.25155 & 0.47566 \\
\hline$\beta$ & 0.98987 & 0.99002 & 0.98986 & 0.99000 \\
\hline$\kappa$ & 0.41184 & 0.57857 & 0.42309 & 0.80306 \\
\hline$\psi_{1}$ & 2.23232 & 2.41409 & 2.22892 & 2.37387 \\
\hline$\psi_{2}$ & 0.27812 & 0.28805 & 0.25515 & 0.27423 \\
\hline$\rho_{\pi}$ & 0.80691 & 0.67133 & 0.00000 & 0.00000 \\
\hline$\rho_{R}$ & 0.89177 & 0.78397 & 0.90167 & 0.83369 \\
\hline$\rho_{g}$ & 0.86592 & 0.86562 & 0.86471 & 0.88184 \\
\hline$\rho_{z}$ & 0.71581 & 0.75238 & 0.71162 & 0.72691 \\
\hline$D$ & 0.21510 & $D=-\rho_{R}$ & 0.12513 & $D=-\rho_{R}$ \\
\hline$\pi^{*}$ & 2.58790 & 2.42552 & 2.54855 & 2.40189 \\
\hline$r^{*}$ & 1.68736 & 1.91675 & 1.82423 & 1.93581 \\
\hline$\sigma_{R}$ & 0.08070 & 0.08897 & 0.09317 & 0.14872 \\
\hline$\sigma_{z}$ & 0.69329 & 0.59847 & 0.69992 & 0.60681 \\
\hline$\sigma_{g}$ & 0.10262 & 0.12009 & 0.10212 & 0.11823 \\
\hline$\sigma_{\pi}$ & 0.18525 & 0.35018 & 0.00000 & 0.00000 \\
\hline$\rho_{g z}$ & 0.84009 & 0.89611 & 0.80383 & 0.83375 \\
\hline
\end{tabular}

NOTE: Bold highlights the estimates of $\sigma_{R}$ across all four models.

Figure 2

Time-Varying Inflation Target, Expected and Actual Inflation

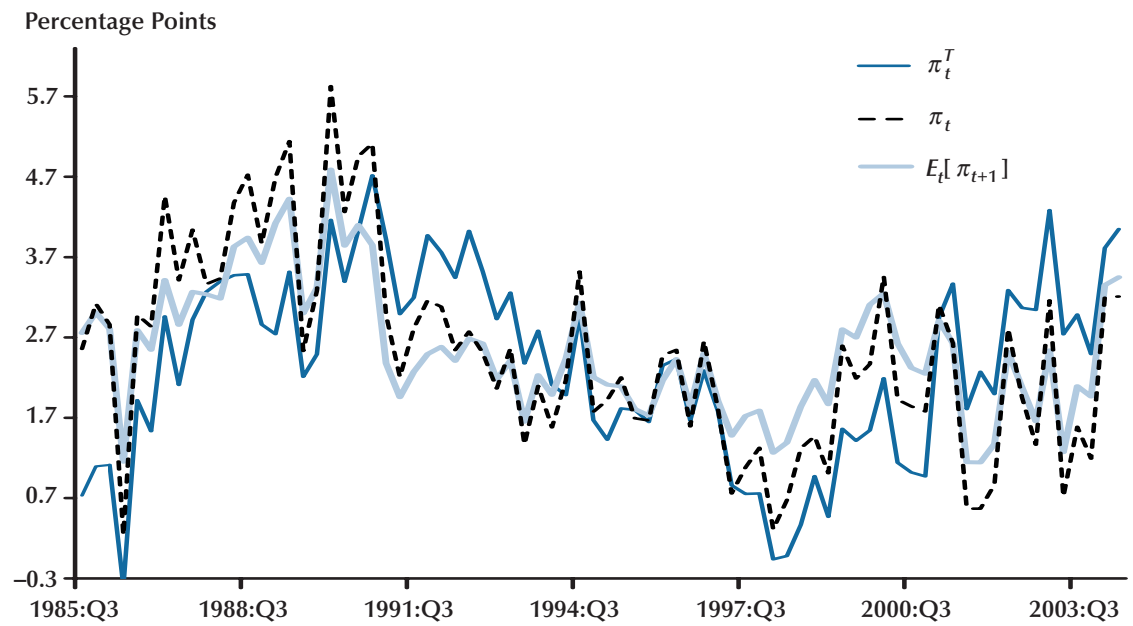




\section{Figure 3}

\section{Discreteness-Adjustment Coefficient}

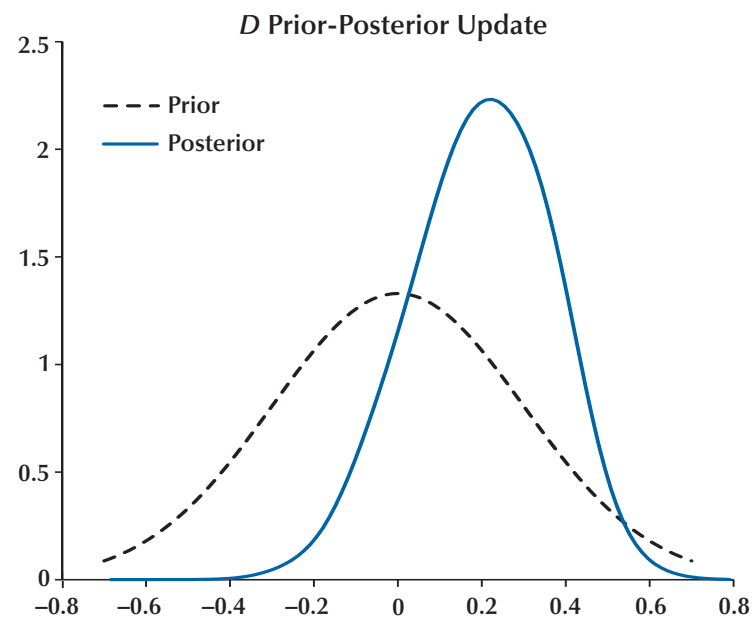

Figure 5

Intertemporal Substitution Elasticity of Consumption

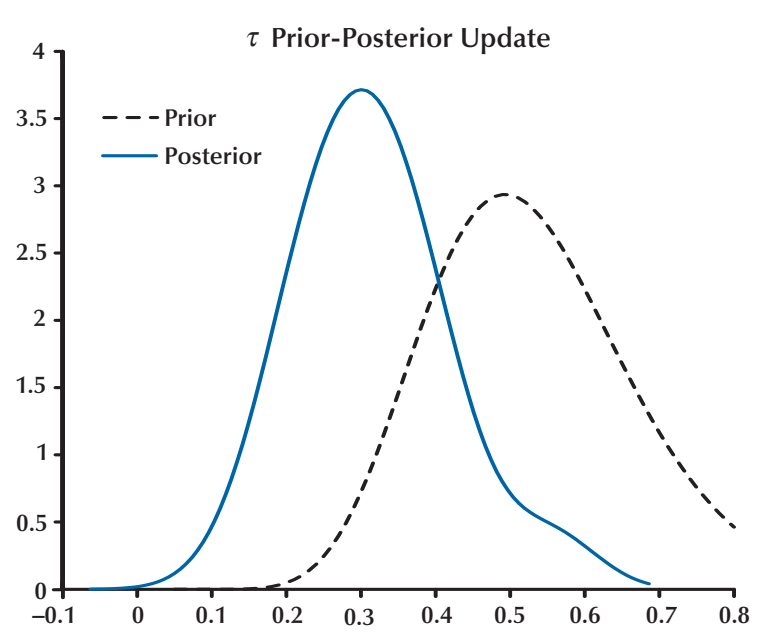

\section{Figure 4}

Time-Varying Inflation Target Coefficient

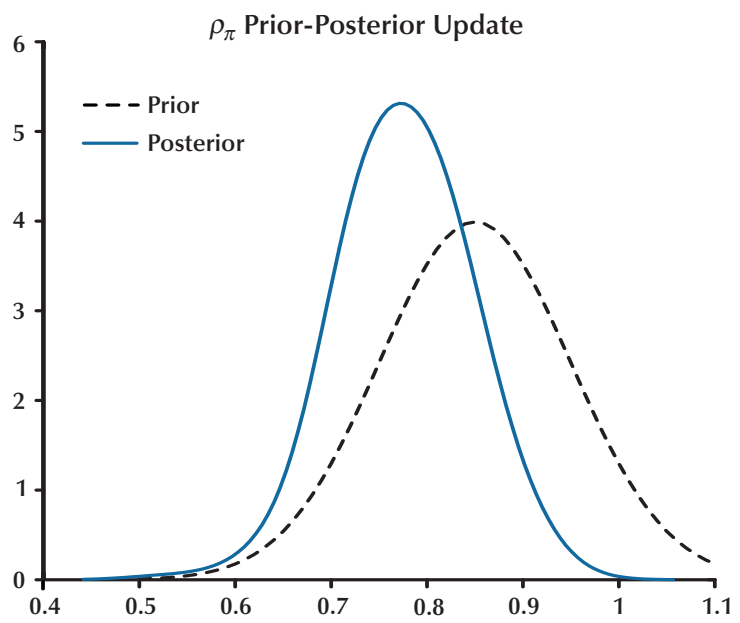

\section{Figure 6}

\section{Slope of Phillips Curve}

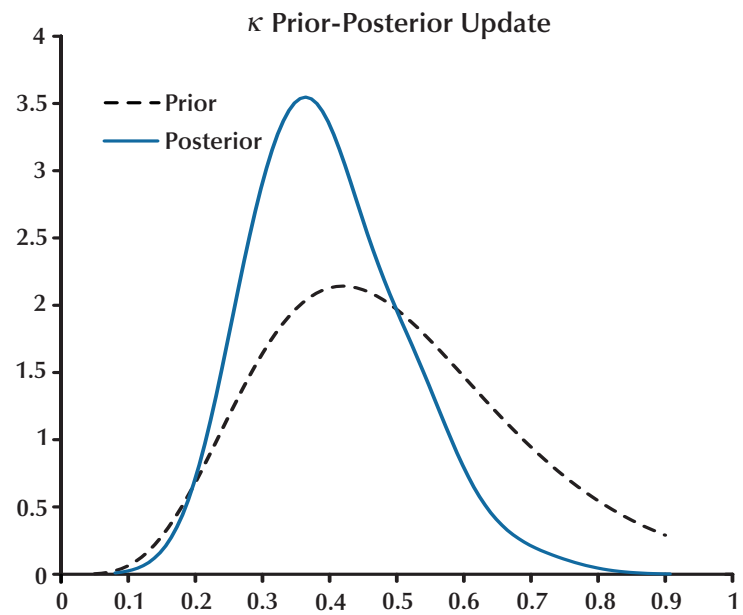




\section{Figure 7}

\section{Taylor Rule Coefficient on Inflation Gap}

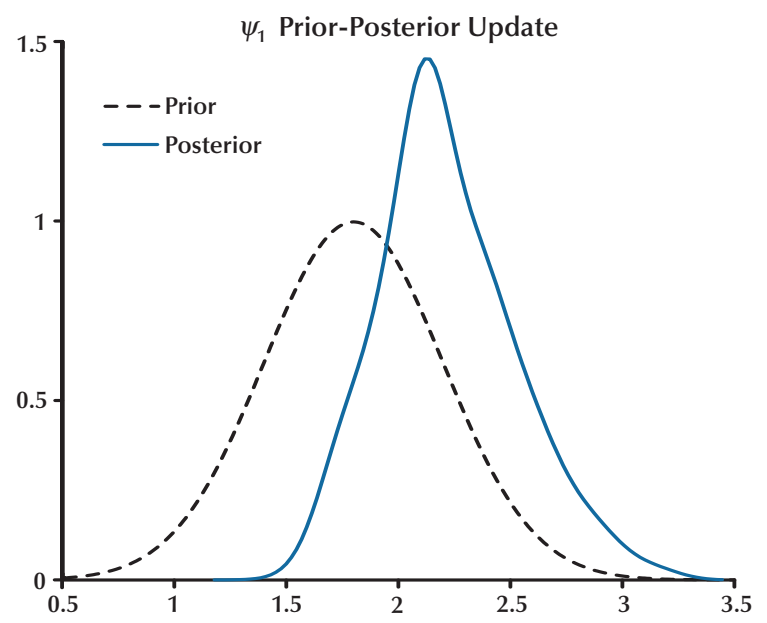

change in the quarterly average of the federal funds rate. Another key result concerns the estimate of the discreteness-adjustment coefficient, $D$. The estimate of $D=0.198$, with a standard deviation of 0.15 , matches the estimates of $D$ from a vector autoregression in Dueker (2002) and from a singleequation Taylor rule in Dueker and Rasche (2004). From the posterior histogram in Figure 3 we see that the posterior mass lies above zero and "light years" above $D=-\rho_{R}$, which is what the standard model without the discreteness adjustment would impose. Figure 3 illustrates that the coefficient on the discreteness adjustment, which has a distribution centered at 0.20 , has a posterior distribution that is determined by the data. The prior distribution is centered at zero and is quite diffuse. Nevertheless, the data are strong enough to move the posterior distribution to the right tail of the prior, although not by enough to rule out $D=0$. Recall that, when $D=0$, the starting point for interest rate smoothing is the end-of-quarter target level of the federal funds rate. The fact that considerable probability mass lies above zero indicates that one expects some continuation of last period's target changes.

The posterior plot of the discount factor, $\beta$ (Figure 8 ), shows that very little probability mass

\section{Figure 8}

\section{Household Discount Factor}

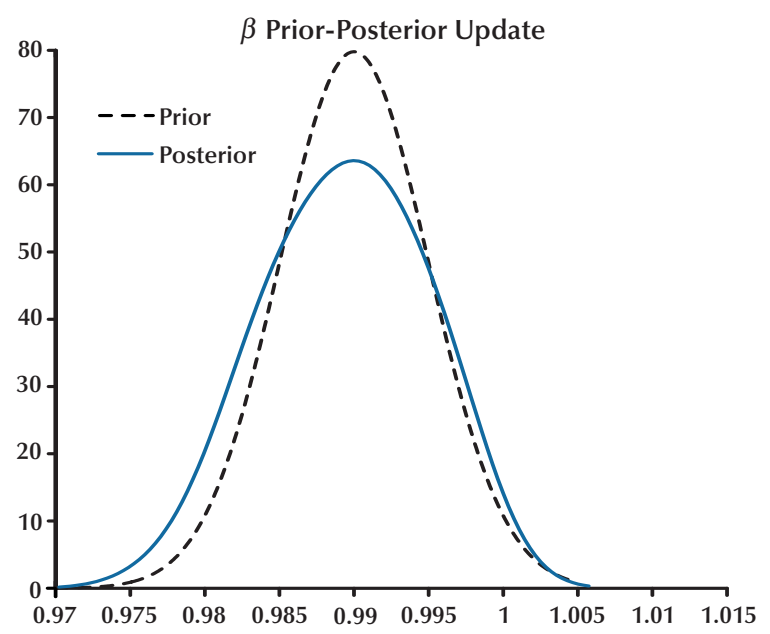

lies above 1.0. Thus, unlike Lubik and Schorfheide (2004) and others, we did not have to tie $\beta$, the rate of discounting the time-separable utility, to other steady-state parameters to infer a value below 1.0. The posterior plots for $\tau$ and $\kappa$, found in Figures 5 and 6, respectively, show that the data shift the posterior to the left of the prior in the presence of the discreteness adjustment. Thus, the discreteness adjustment leads to the conclusion that monetary policy faces a flatter Phillips curve than the basic model would suggest.

From the posterior plot on Figure 7 we see that the feedback parameter from the inflation gap, $\psi_{1}$, shows that the posterior distribution is unambiguously above 1.0. That is, the data strongly support monetary policy determinacy in the post-1984 period.

We turn next to our estimates of the timevarying inflation target. The time-varying inflation target inferred from the data has an unconditional mean of about 2.5 percent, and its deviations are persistent, with an autoregressive coefficient of $\rho_{\pi}=0.78$. Figure 2 plots this model-implied inflation target against actual inflation and modelimplied inflation expectations. During this sample period, the model-implied inflation target often moved in the same direction as actual inflation. 


\section{Belaygorod and Dueker}

Target and actual inflation have a positive correlation (0.65), but it is still much lower than the 0.96 correlation between actual and expected inflation.

\section{IMPULSE RESPONSES}

Impulse response functions illustrate the different economic implications of the models specified with and without the discreteness adjustment. In order to calculate an impulse response for the model with the discreteness adjustment, it is necessary to make some assumptions concerning the interaction between the target federal funds rate and the effective federal funds rate. The first assumption is that in the simulated quarters the Federal Reserve achieves on average its target for the daily effective rate. The second is that the starting point for the impulse simulation is one where the effective rate equals the target. For the third assumption, we consider two cases: one where the federal funds target is shocked halfway through a quarter (the empirically relevant case) and one where the target is shocked at the very beginning of the quarter. The latter case facilitates a comparison between the coefficients pertaining to models estimated with and without the discreteness adjustment. These timing assumptions pin down the response of the discreteness adjustment, $R^{T}-R$, to an interest rate shock. With these assumptions, at the time of the interest rate shock, the change in the quarterly average equals $(1-\lambda)$ times the change in the target, where $\lambda$ is the portion of the quarter that has elapsed when the target shock occurs. Thus, the change in the discreteness-adjustment term $\left(R^{T}-R\right)$ in response to an interest rate shock equals $\lambda /(1-\lambda)$ times the size of the shock.

When the simulated target change is assumed to take place right at the beginning of the quarter such that $\lambda=0$, the discreteness-adjustment term does not enter the impulse response and the only difference between the models with and without the discreteness adjustment is that the estimated coefficients differ, depending on whether $D$ is restricted to zero. The impulse responses corresponding to the case where $\lambda=0$ are shown in the left-side panel of Figure 6. They show that, even when the simulated target change takes place at the beginning of the quarter, such that no gap is opened between the quarterly average and the target rate, an interest rate shock is estimated to have a larger impact in the model estimated with the discreteness adjustment.

The case where $\lambda=0.50$ has greater empirical relevance because, from 1984 through 1993, 50.1 percent of the weighted mass of target changes took place in the second half of the quarters, on average, and from 1994 through May 2005 the same measure is 52.2 percent. The impulse responses for these models stem from equation (A3) in the appendix, which shows that when the discreteness adjustment is omitted from the model, then the impulse responses are those of a firstorder vector auto regression, VAR(1). The effect of the discreteness adjustment is to change the structure of the model to include a moving average component-a VARMA (1,1). The additional response comes from the discreteness-adjustment term, where the response is proportional to $\lambda /(1-\lambda)$, as discussed above. Consequently, the impulse responses from the VARMA $(1,1)$ specification will show an extra kink from the movingaverage component.

The left panel of Figure 9 shows the discreteness adjustment leads to estimated coefficients that imply stronger impulse responses (in absolute value) to a monetary policy shock, relative to the model without the discreteness adjustment. The right-hand panel of Figure 9 shows that the discreteness adjustment does what it is supposed to do. A 100-basis-point shock to the target federal funds rate eventually has the same effect-whether it is implemented at the beginning or the middle of a quarter-once it is fully reflected in the quarterly average. This equivalence holds because the model with the discreteness adjustment accurately predicts the consequences of a mid-quarter target change for the quarterly average. The model without the disceteness adjustment, in contrast, would treat the change in the quarterly average in the subsequent period as a surprise. In this context, the VAR(1) structure of the DSGE model acts as a limitation because Dueker (2002) showed 


\section{Figure 9}

\section{Impulse Response Functions}

Response of Output to Monetary Policy Shock When 100-Basis-Point Target Change Occurs at Beginning of Quarter

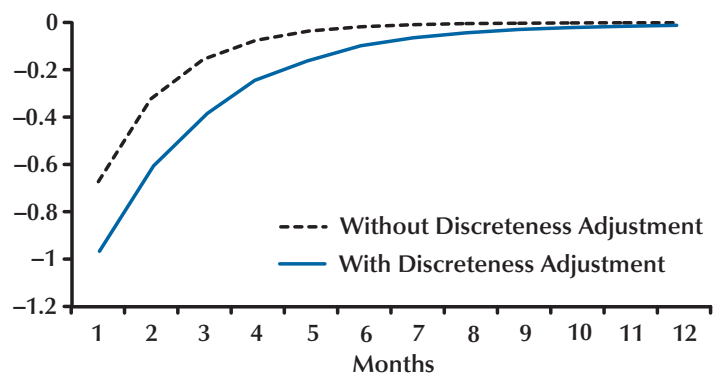

Response of Federal Funds Rate to Own Shock When 100-Basis-Point Target Change Occurs at Beginning of Quarter

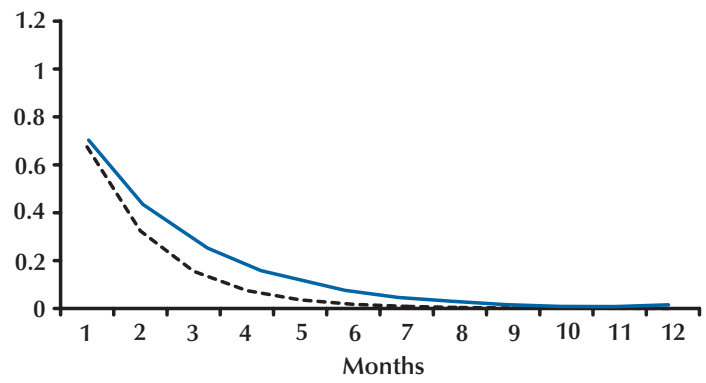

Response of Inflation to Monetary Policy Shock When 100-Basis-Point Target Change Occurs at Beginning of Quarter

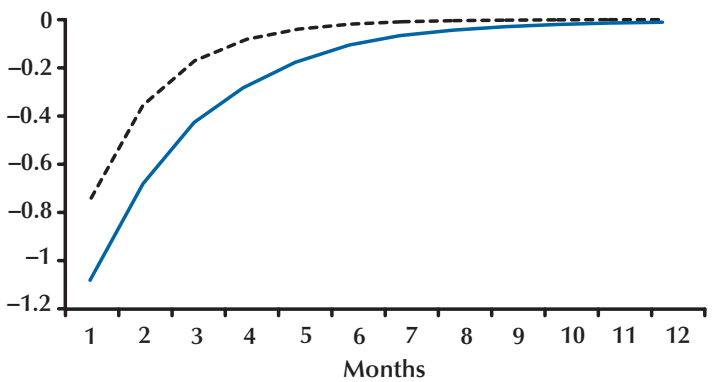

Response of Output to Monetary Policy Shock When 100-Basis-Point Target Change Occurs in Middle of Quarter vs. Beginning of Quarter

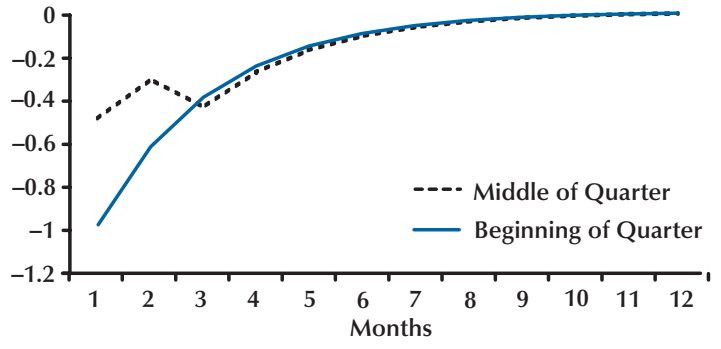

Response of Federal Funds Rate to Own Shock When 100-Basis-Point Target Change Occurs in Middle of Quarter vs. Beginning of Quarter

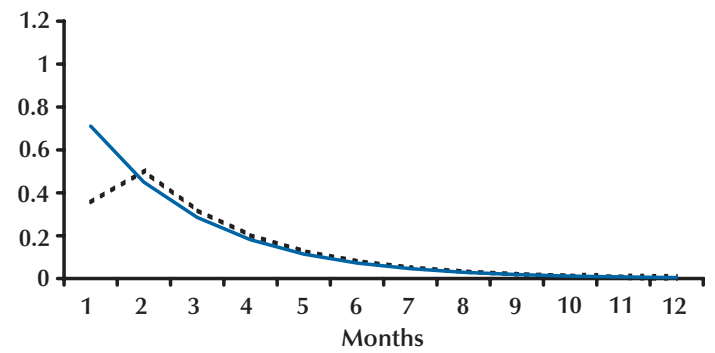

Response of Inflation to Monetary Policy Shock When 100-Basis-Point Target Change Occurs in Middle of Quarter vs. Beginning of Quarter

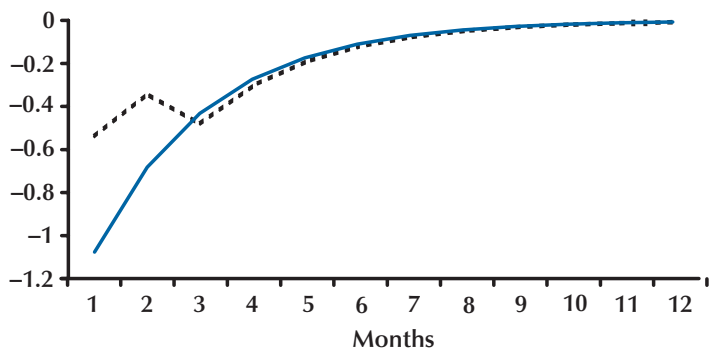


that the federal funds rate equation in a higherorder VAR can imply the hump-shaped response of the quarterly average to its own shock. The conclusion is that, since many linear DSGE models imply a first-order VAR structure, it is even more important to include the discreteness adjustment than it is in higher-order nonstructural VARs.

\section{CONCLUSIONS}

We have made a key enhancement to the Taylor-type monetary policy equation analyzed in estimated DSGE models: We allow the interest rate smoothing to start at a point other than last quarter's average because last quarter's average does not fully reflect the discrete target changes policymakers made in that quarter. Our estimates indicate that the starting point for interest rate smoothing is the end-of-period target federal funds rate plus a small degree of momentum built into the starting point. This enhancement leads to a dramatic fall in the standard error of the interest rate equation on the order of 40 percent. Thus, previous conclusions regarding determinacy and the degree of interest rate smoothing are subject to omitted error bias in the absence of such a discreteness adjustment. We also find that the importance of allowing for a time-varying inflation target is greatly reduced in our post-1984 data set, provided that the discreteness adjustment is included. Without the discreteness adjustment, the time-varying inflation appears to be an indispensable feature of the data.

The discreteness adjustment also leads to lower estimates of the interest sensitivity of output and a flatter estimate of the Phillips curve, relative to the baseline model. On balance, monetary policy would appear to have more influence on the behavior of the real economy when one accounts for the discreteness of monetary policy actions.

\section{REFERENCES}

Blanchard, Olivier J. and Kahn, Charles M. "The Solution to Linear Difference Models Under Rational Expectations." Econometrica, July 1980, 48(5), pp. 1305-11.
Chib, Siddhartha and Greenberg, Edward. "Bayes Inference in Regression Models with ARMA (p,q) Errors." Journal of Econometrics, September/ October 1994, 64(1-2), pp. 183-206.

Chib, Siddhartha. "Understanding the MetropolisHastings Algorithm.” American Statistician, November 1995, 49(4), pp. 327-35.

Chib, Siddhartha. "Markov Chain Monte Carlo Simulation Methods in Econometrics.” Econometric Theory, August 1996, 12(3), pp. 409-31.

Chib, Siddhartha. "Markov Chain Monte Carlo Methods: Computation and Inference," in James Heckman and Edward Leamner, eds., Handbook of Econometrics. Volume 5. Amsterdam: NorthHolland, 2001.

Christiano, Lawrence; Eichenbaum, Martin and Evans, Charles. "Nominal Rigidities and the Dynamic Effects of a Shock to Monetary Policy." Journal of Political Economy, February 2005, 113(1), pp. 1-45.

Clarida, Richard; Galí, Jordi and Gertler, Mark. "Monetary Policy Rules and Macroeconomic Stability: Evidence and Some Theory." Quarterly Journal of Economics, February 2000, 115(1), pp. 147-80.

Dueker, Michael J. “The Monetary Policy Innovation Paradox in VARs: A 'Discrete' Explanation.” Federal Reserve Bank of St. Louis Review, March/ April 2002, 84(4), pp. 43-49.

Dueker, Michael J. and Rasche, Robert H. "Discrete Policy Changes and Empirical Models of the Federal Funds Rate.” Federal Reserve Bank of St. Louis Review, November/December 2004, 86(6), pp. 61-72.

English, William B.; Nelson, William R. and Sack, Brian P. "Interpreting the Significance of the Lagged Interest Rate in Estimated Monetary Policy Rules." Contributions to Macroeconomics, 2003, 3(1).

Gavin, William T.; Keen, Benjamin D. and Pakko, Michael R. "The Monetary Instrument Matters." Working paper 2004-026B, Federal Reserve Bank of St. Louis, 2005. 
Gavin, William T.; Kydland, Finn E. and Pakko, Michael R. "Monetary Policy, Taxes, and the Business Cycle." Working paper 2004-017B, Federal Reserve Bank of St. Louis, 2005.

Ireland, Peter. "Changes in the Federal Reserve's Inflation Target: Causes and Consequences." Unpublished manuscript, Boston College, January 2005.

Kollmann, Robert. "The Exchange Rate in a DynamicOptimizing Business Cycle Model with Normal Rigidities: A Qualitative Investigation." Journal of International Economics, December 2001, 55(2), pp. 243-62.

Kollmann, Robert. "Monetary Policy Rules in the Open Economy: Effects on Welfare and Business Cycles." Journal of Monetary Economics, July 2002, 49(5), pp. 989-1015.

Lubik, Thomas A. and Schorfiede, Frank. "Testing for Indeterminacy: An Application to U.S. Monetary Policy." American Economic Review, March 2004, 94(1), pp. 190-217.

McCallum, Bennett T. and Nelson, Edward. "An Optimizing IS-LM Specification for Monetary Policy and Business Cycle Analysis." Journal of Money, Credit, and Banking, August 1999, 31(3 Part 1), pp. 296-316.

Orphanides, Athanasios. "Monetary Policy Rules Based on Real-Time Data." American Economic Review, September 2001, 91(4), pp. 964-85.

Rotemberg, Julio J. and Woodford, Michael. "Interest Rate Rules in an Estimated Sticky Price Model," in John B. Taylor, ed., Monetary Policy Rules. Chicago: University of Chicago Press, 1999.
Rudebusch, Glenn D. “Term Structure Evidence on Interest Rate Smoothing and Monetary Policy Inertia." Journal of Monetary Economics, September 2002, 49(6), pp. 1161-87.

Sack, Brain. "Does the Fed Act Gradually? A VAR Analysis." Journal of Monetary Economics, August 2000, 46(1), pp. 229-56.

Sims, Christopher A. "Solving Linear Rational Expectations Models." Computational Economics, October 2002, 20(1), pp. 1-20.

Smets, Frank and Wouters, Raf. “An Estimated Dynamic Stochastic General Equilibrium Model for the Euro Area." Journal of the European Economic Association, September 2003, 1(5), pp. 1123-75.

Smets, Frank and Wouters, Raf. "Comparing Shocks and Frictions in U.S. and Euro Area Business Cycles: A Bayesian DSGE Approach.” Journal of Applied Econometrics, 2005, 20(1), pp. 161-83.

Taylor, John B. "Discretion versus Policy Rules in Practice." Carnegie-Rochester Conference Series on Public Policy, December 1993, 39, pp. 195-214.

Woodford, Michael. Interest and Prices: Foundations of a Theory of Monetary Policy. Princeton: Princeton University Press, 2003a.

Woodford, Michael. "Optimal Interest-Rate Smoothing." Review of Economic Studies, October 2003b, 70(4), pp. 861-86. 


\section{APPENDIX}

\section{THE DSGE MODEL SOLUTION WITH PREDETERMINED EXOGENOUS REGRESSORS}

Sims (2002) introduces a general method for solving DSGE models. Here we show how to adapt his solution methodology to the same setup enriched by the presence of predetermined regressors. Consider a DSGE model of the following canonical form:

$$
\Gamma_{0} s_{t}=\Gamma_{1} s_{t-1}+C+\Psi \varepsilon_{t}+\Pi \eta_{t}+D \Delta_{t-1},
$$

where, at time $t, s_{t}$ is the vector of state variables, $\varepsilon_{t}$ is a vector of structural shocks, $\eta_{t}$ is a vector of expectational errors, $\Delta_{t-1}$ is a vector of predetermined regressors (not present in the model considered by Sims, 2002) and $\Gamma_{0}, \Gamma_{1}, C, \Psi, \Pi, D$ are parameter matrices.

Following Sims (2002) we apply a generalized Schur $Q Z$ decomposition, $\left(\Gamma_{0}, \Gamma_{1}\right)=\left(Q^{\prime} \Lambda Z^{\prime}, Q^{\prime} \Omega Z^{\prime}\right)$; partition the resulting system into non-explosive (denoted by subscript 1) and explosive components (denoted by subscript 2); and use "solution uniqueness" and "stability" conditions worked out in Sims (2002) to write

$$
\begin{aligned}
& \left(\begin{array}{cc}
I & -\Phi \\
0 & \Lambda_{22}^{-1}
\end{array}\right)\left(\begin{array}{ll}
\Lambda_{11} & \Lambda_{12} \\
0 & \Lambda_{22}
\end{array}\right)\left(\begin{array}{l}
\omega_{1}(t) \\
\omega_{2}(t)
\end{array}\right)=\left(\begin{array}{cc}
I & -\Phi \\
0 & 0
\end{array}\right)\left(\begin{array}{cc}
\Omega_{11} & \Omega_{12} \\
0 & \Omega_{22}
\end{array}\right)\left(\begin{array}{l}
\omega_{1, t-1} \\
\omega_{2, t-1}
\end{array}\right)+ \\
& \left(\begin{array}{cc}
I & -\Phi \\
0 & \left(\Lambda_{22}-\Omega_{22}\right)^{-1}
\end{array}\right)\left(\begin{array}{l}
Q_{1} \\
Q_{2}
\end{array}\right) C+\left(\begin{array}{cc}
I & -\Phi \\
0 & 0
\end{array}\right)\left(\begin{array}{l}
Q_{1} \\
Q_{2}
\end{array}\right)\left(\Psi \varepsilon_{t}+D \Delta_{t-1}\right),
\end{aligned}
$$

where $\omega(t)=Z^{\prime} s_{t}, \Phi=Q_{1} \Pi\left(Q_{2} \Pi\right)^{-1}$ and I,0 denote identity and zero matrices, respectively, with dimensionality easily deduced from the preceding equation.

Therefore, the solution to the DSGE model in equation (A1) could be written as

$$
s_{t}=\Theta_{1} s_{t-1}+\Theta_{C}+\Theta_{0} \varepsilon_{t}+D^{*} \Delta_{t-1},
$$

where $\Theta_{1}, \Theta_{C}, \Theta_{0}$ were derived in Sims (2002) and are identical to those variables in our expanded model. The coefficient $D^{*}$ can be found by focusing on the last term in equation (A2):

$$
\begin{aligned}
& \left(\begin{array}{cc}
I & -\Phi \\
0 & \Lambda_{22}^{-1}
\end{array}\right)^{-1}\left(\begin{array}{cc}
I & -\Phi \\
0 & 0
\end{array}\right)\left(\begin{array}{l}
Q_{1} \\
Q_{2}
\end{array}\right)\left(\Psi \varepsilon_{t}+D \Delta_{t-1}\right)= \\
& \left(\begin{array}{c}
Q_{1}-\Phi Q_{2} \\
0
\end{array}\right)\left(\Psi \varepsilon_{t}+D \Delta_{t-1}\right)=\left(\begin{array}{c}
Q_{1} \\
Q_{2}
\end{array}\right)\left(I-\Pi\left(Q_{2} \Pi\right)^{-1} Q_{2}\right)\left(\Psi \varepsilon_{t}+D \Delta_{t-1}\right)
\end{aligned}
$$

If we define $\Pi^{*}=\left(\Gamma_{0}\right)^{-1} \Pi, \Psi^{*}=\left(\Gamma_{0}\right)^{-1} \Psi$, then we can use equations (A3) and (A4) to find that ${ }^{3}$

$$
\begin{aligned}
& \Theta_{0}=\Psi^{*}-\Pi^{*}\left(Q_{2} \Pi\right)^{-1} Q_{2} \Psi \\
& D^{*}=\left(\Gamma_{0}\right)^{-1} D-\Pi^{*}\left(Q_{2} \Pi\right)^{-1} Q_{2} D .
\end{aligned}
$$

\footnotetext{
3 If $\Gamma_{0}$ is not invertible, we can still use its generalized Schur decomposition representation to carry out this analysis using more clumsy
} notation in terms of partitions of $Q, \Lambda, Z$ as in Sims (2002). 
All this time $\Psi \varepsilon_{t}$ and $D \Delta_{t-1}$ were treated symmetrically in the derivations just noted, and as a result the final formulas noted previously look the same: The new coefficient equals $\left(\Gamma_{0}\right)^{-1}$ times the old coefficient plus correction for expectational error coming from the "solution existence" condition:

$$
Q_{2} D \Delta_{t-1}+Q_{2} \Psi \varepsilon_{t}+Q_{2} \Pi \eta_{t}=0
$$

which allows us to solve for expectational error as a function of structural shocks, predetermined regressors, and parameters:

$$
\eta_{t}=-\left(\left(Q_{2} \Pi\right)^{-1} Q_{2} D \Delta_{t-1}+\left(Q_{2} \Pi\right)^{-1} Q_{2} \Psi \varepsilon_{t}\right) .
$$

However, there is an important distinction between structural shocks and predetermined regressors. We require that expectational errors depend only on the shocks and are independent of predetermined regressors. From the econometric prospective, this requirement amounts to setting the coefficient on $\Delta$ in the regression of $\eta$ on $\varepsilon$ and $\Delta$ to zero:

$$
\left(Q_{2} \Pi\right)^{-1} Q_{2} D=0
$$

Then, the equations in (A5) become

$$
\begin{aligned}
& \Theta_{0}=\Psi^{*}-\Pi^{*}\left(Q_{2} \Pi\right)^{-1} Q_{2} \Psi \\
& D^{*}=\left(\Gamma_{0}\right)^{-1} D .
\end{aligned}
$$


